\title{
Suggested role of Vitamin D supplementation in COVID-19 severity
}

\author{
Parviz Afshar', Mohammad Ghaffaripour², Hamid Sajjadi
}

\author{
'Hospital Director, Iranian Hospital Dubai, Dubai, UAE'ICU Director, Iranian Hospital Dubai, Dubai, UAE \\ ${ }^{3}$ Neuro-Ophthalmology Director, Iranian Hospital Dubai, Dubai, UAE \\ Corresponding Author: Hamid Sajjadi (Email: hsajjadi@yahoo.com)
}

\section{Dear Editor in chief}

\section{The Journal of Contemporary medical sciences}

Vitamin D, a pre-hormone, regulates and/or affects multiple functions such as immune-, coagulation-, cardiovascular-, central nervous system, inflammation, cancer rates, deep-vein-thrombosis, sleep-apnea, and respiratory tract infections (RTIs). ${ }^{1-8}$ The role of vitamin D in reducing RTI is outstanding as reported by a meta-analysis. ${ }^{2}$ Our first reference is a must read document with "over 150 references" regarding the RTI reduction in patients with Vitamin D level (VDL) $>40-\mathrm{ng} / \mathrm{mL}$ versus those $<20-\mathrm{ng} / \mathrm{mL} .{ }^{1}$ VDL and Covid severity has been well-shown in a very recent study. ${ }^{9}$

The two most important causes of COVID-19 severity, needing ventilators and possible death are:

1. Cytokine Storm and Complement dysfunction ending on a death spiral of respirator and drowning in their fluids..$^{2-6}$

2. Hyper-coagulation state ending with multiple peripheral system diseases, such as cardiomyopathy or encephalopathy. ${ }^{7,8}$ Vitamin D plays a major role in both processes. ${ }^{2-9}$

Over 5,000 patients of neuro-ophthalmology department had VDL checked from 2010 to 2020; 66\% had deficiency $(<20-\mathrm{ng} / \mathrm{mL})$, prevalence changed to $83 \%$ if $<30-\mathrm{ng} / \mathrm{mL}$ was chosen, and $93 \%$ when $<35-\mathrm{ng} / \mathrm{mL}$ was set as deficient. In between 2010 and 2012 after patients stopped vitamin D once reaching normal levels, VDD recurred in all cases after 4 month follow-ups. Table 1 shows suggested cut-offs accepted by most endocrine societies.

VDD is multifactorial and endemic worldwide. Insult to vitamin D may come from artificial coloring and flavoring found in processed foods, soft drinks, lack of sun exposure, any chronic illness such as diabetes, hypertension, chronic kidney disease, obesity, and more. Heat (avoiding sun exposure) and color of skin (less UV effect for Vitamin D in darker skins) cause African countries to have higher VDD than the Scandinavian nations. With inadequate sun exposure and constant poisoning of vitamin $\mathrm{D}$ by food additives and chronic illnesses, lifelong

\begin{tabular}{cc}
\hline Table 1. Typical endocrine societies guideline. \\
\hline Very Low & $<20 \mathrm{ng} / \mathrm{mL}$ \\
Insufficient & $21-29 \mathrm{ng} / \mathrm{mL}$ \\
Sufficient & $30-60 \mathrm{ng} / \mathrm{mL}$ \\
Ideal & $\mathbf{4 0 - 6 0 ~} \mathbf{n g} / \mathbf{m L}$ \\
Considered safe & Up to $100 \mathrm{ng} / \mathrm{mL}$ \\
Toxic & $>120-150 \mathrm{ng} / \mathrm{ml}$ \\
\hline
\end{tabular}

Vitamin D supplementation (LLVDS) for urban residents is a must. We have only seen a few good VDL $(>40-n g / m L$ without Vitamin D supplement), in patients that live in rural areas who consume their own farms' food including milk with no soft drink usage. The majority of people who consume processed foods encounter VDD. In the latter subgroup, many clinician stop supplementation when Vitamin D reaches normal levels and this will almost always result in VDD recurrence.

In the neuro-ophthalmology department, we have been using 70-100-IU of Vitamin D3/Kg/Day for maintenance since 2010. We used 70-IU/Kg/Day in patients with normal eye exams and $100-\mathrm{IU} / \mathrm{Kg} / \mathrm{Day}$ for retinal and optic neuropathy patients. After supplementation all patients had VDL $>40 \mathrm{ng} / \mathrm{mL}$ with some in-between 60 and 89 , and none over 90 in the last 9 years. In a subset of over 500 patients on continuous 1-8-year-treatment/ follow-up, we have not seen even one case of toxicity.

Since COVID-19 outbreak, we have had 21 patients, all with $\mathrm{VDL}>40 \mathrm{ng} / \mathrm{mL}$ (including 2 health-care workers and several with chronic disease, like diabetes, hypertension and obesity), who were on regular follow-up for their eye disease informed us that, they had COVID-19 but the hospitalization period was all under 4 days. This finding prompted us recommending this dosage for all other cases in the hospital.

Subsequently, we started supplementation of Vitamin D as routine care from early June 2020 in all SARS-CoV-2+ and COVID-19 patients (SARS-CoV-2+ with typical signs and symptoms that needed admission) in the Iranian Red-Crescent Hospital in Dubai, a dramatic and complete resolution of ICU admissions was observed in the last 8 weeks. We cannot overemphasize the role of Vitamin D in controlling all infectious diseases especially in COVID-19. ${ }^{1}$ We had no patients with initial Vitamin D levels of $>40$ that required more than $2-3$ days of hospitalization, hence no cytokine storm, hypercoagulation, nor complement deregulation occurred. Prior to this change, we had several deaths of COVID-19 patients on respirators.

Our Vitamin D supplementation (in addition to the required therapies such as Chloroquin, Remdesivir or others) was:

1. 300,000-IU, IM vitamin D3 once, followed by:

2. $100-\mathrm{IU} / \mathrm{Kg} / \mathrm{Day}$.

3. We know that, one bullous injection is not enough and patient must continue with daily dosage for maintenance. This regimen is very safe and very far from toxicity.

4. It is also a known fact that hydroxychloroquin decreases VDL.

5. Checked Vitamin D on oral Vitamin D3 in hospitalized patients but 1 week after IM dosage.

6. If patient recovers in shorter period they are discharged on daily dosage and VDL is checked in 3 months $\underline{\boldsymbol{B U T}}$ 6 days after last dosage. 
Because Vitamin D3 is fat soluble, raising its level is definitely weight-related. That is why in many studies with a constant dose it is difficult to raise VDL in obese patients. This may be the main cause of cytokine storm and death in young healthy obese persons.

Although a daily dose of $70-100-\mathrm{ng} / \mathrm{mL} / \mathrm{Kg}$ is preferred, since the 50,000-IU capsule of Vitamin D3 supplement is widely available, we would recommend that individuals between 50 and $100-\mathrm{Kg}$ to take $50,000-\mathrm{IU}$ of Vitamin D3 weekly in order to protect against Cytokine Storm and hypercoagulation syndromes of COVID-19 and other respiratory viruses. Under 50 and over 100-kg need the daily calculated dose.

For other patients/healthy individuals LLVDS for all ages: $<30-\mathrm{ng} / \mathrm{mL}$

1. Vitamin D3, 300,000-IU one IM injection.

2. Vitamin D3, 70-100 IU/Kg/Day. For example, at least: $10-\mathrm{Kg}=700-\mathrm{IU}$-daily, $70-\mathrm{kg}=5,000-\mathrm{IU}$-daily, $100-\mathrm{kg}=$ 7,000-IU-daily.

\section{$30-40 \mathrm{ng} / \mathrm{mL}$}

1. Vitamin D3, 70-100 IU/Kg/Day.

\section{$>45-\mathrm{ng} / \mathrm{mL}$ :}

No additional treatment needed, recheck Vitamin D in few days for possible error and if in the same range, then recheck every 4 months.
The correct time for checking VDL is 6 days after last dose of Vitamin D3 to avoid artificial high levels.

Unfortunately, many colleagues are afraid of an extremely-rare vitamin D toxicity (VDT). VDT is reported in usage over 40,000 -IU/day. ${ }^{10}$ There are 88 diseases including sleep disorder that may resolve or reduce severity with VDL of 60-80-ng/Ml. ${ }^{4}$ We achieved this by using $100-\mathrm{IU} / \mathrm{Kg} / \mathrm{Day}$ in our patients and with LLVDS, without VDT.

Because of recently available scientific evidence and reported numerous new functions of this pre-hormone, we would like to propose changing the VDL to $40-100-\mathrm{ng} / \mathrm{Ml}$ as normal and consider below 40 as deficient.

\section{References:}

1. https://www.mdpi.com/2072-6643/12/4/988

2. https://www.bmj.com/content/356/bmj.i6583

3. https://www.ncbi.n/m.nih.gov/pmc/articles/PMC6164284/ \#: :text=Multiple\%20studies\%20have\%20shown\%20that, for\%20cancer\%20prevention\%20and\%20therapy

4. VitaminDwiki.com

5. https://europepmc.org/article/ppr/ppr149846

6. https://www.jstage.jst.go.jp/article/jnsv/63/3/63_155/_pdf

7. https://www.mdpi.com/2218-273X/9/11/649/xml

8. https://www.ncbi.n/m.nih.gov/pmc/articles/PMC4069050/

9. https://www.ncbi.n/m.nih.gov/pmc/articles/PMC7455115/

10. https://www.merckmanuals.com/professional/nutritional-disorders/ vitamin-deficiency-dependency-and-toxicity/vitamin-d-toxicity?

This work is licensed under a Creative Commons Attribution-NonCommercial 3.0 Unported License which allows users to read, copy, distribute and make derivative works for non-commercial purposes from the material, as long as the author of the original work is cited properly. 